\title{
A importância do banco de dentes humanos: relato de experiência
}

The importance of the human teeth bank in public health: experience report

\author{
La importancia del banco de dientes humanos: \\ relato de experiencia \\ Marcos Sérgio ENDO ${ }^{1}$ \\ Isabela Regina Grilo SILVA ${ }^{2}$ \\ Márcia Cristina da SILVA ${ }^{2}$ \\ Raquel Sano Suga TERADA ${ }^{1}$ \\ Najara Barbosa da ROCHA ${ }^{\mathbf{1}}$ \\ Professor(a) Adjunto do Departamento de Odontologia, da Universidade Estadual de Maringá-UEM, \\ 87020.900 Maringá-PR, Brasil \\ Aluna da graduação do Departamento de Odontologia da Universidade Estadual de Maringá-UEM, \\ 87020.900 Maringá-PR, Brasil
}

\begin{abstract}
Resumo
O banco de dentes humanos (BDH) do Departamento de Odontologia (DOD) da Universidade Estadual de Maringá (UEM) trata-se de um núcleo sem fins lucrativos, com participação de docentes e discentes voluntários, objetivando documentar a procedência e destino dos dentes humanos extraídos, a fim de suprir as necessidades acadêmicas para o aprendizado dos alunos e o fornecimento de dentes humanos para a pesquisa. Este trabalho tem como objetivo relatar a experiência do BDH do DOD-UEM. Ele é mantido por meio de doações dos pacientes atendidos na Clínica Odontológica desta Universidade, unidades básicas de saúde e outras fontes. O BDH distribui os dentes extraídos, zela pela eliminação da infecção cruzada e diminui o manuseio indiscriminado de dentes extraídos. Com isso, conclui-se que o BDH é de extrema importância para a universidade, valorizando o dente como órgão e possibilitar a execução de trabalhos de pesquisa científica.
\end{abstract}

Descritores: Dente; Coleta de Tecidos e Órgãos; Odontologia.

\begin{abstract}
The human teeth bank of the Department of Dentistry of the State University of Maringá is a non-profit center with the participation of volunteer teachers and students, aiming to document the origin and destination of human teeth In order to meet the academic needs for student learning and the provision of human teeth for research. This work aimed to report the experience of the human teeth bank of the Department of Dentistry of the State University of Maringá. It is maintained through donations of patients attended at the Dental Clinic of this University, basic health units and other sources. The human teeth bank distributes extracted teeth, eliminates cross-infection, and reduces the indiscriminate handling of extracted teeth. With this, it is concluded that the human teeth bank is extremely important for the university, valuing the tooth as an organ and enabling the execution of scientific research work.
\end{abstract}

Descriptors: Tooth; Tissue and Organ Harvesting; Dentistry.

\section{Resumen}

El banco de dientes humanos (BDH) del Departamento de Odontología (DOD) de la Universidad Estatal de Maringá (UEM) se trata de un núcleo sin fines de lucro, con participación de docentes y discentes voluntarios, con el objetivo de documentar la procedencia y destino de los dientes humanos extraídos para satisfacer las necesidades académicas para el aprendizaje de los alumnos y el suministro de dientes humanos para la investigación. Se ha intentado relatar la experiencia del BDH del DOD-UEM. Se mantiene por medio de donaciones de los pacientes atendidos en la Clínica Odontológica de esta Universidad, unidades básicas de salud y otras fuentes. El BDH distribuye los dientes extraídos, zana por la eliminación de la infección cruzada y disminuye el manejo indiscriminado de dientes extraídos. Con ello, se concluye que el $\mathrm{BDH}$ es de extrema importancia para la universidad, valorizando el diente como órgano y posibilitando la ejecución de trabajos de investigación científica.

Descriptores: Diente; Recolección de Tejidos y Órganos; Odontología.

\section{INTRODUÇÃO}

Os dentes são considerados órgãos, e como tais, devem ser tratados, valorizados e ter a sua origem conhecida ${ }^{1}$. Para cumprir com estes objetivos torna-se essencial um Banco de Dentes Humanos inserido na Universidade.

Atualmente se tem conhecimento de que tecidos do corpo são fontes de DNA, sendo assim, dentes que são preservados, identificados e armazenados apropriadamente em um BDH auxilia a Odontologia forense nas pesquisas com DNA e na identificação humana ${ }^{2}$.

$\mathrm{Na}$ Odontologia, dentro do ambiente universitário, sempre foi comum a existência da prática da comercialização ilegal de dentes retirados de cemitérios, o que causa uma desvalorização do dente como órgão ${ }^{3}$, além de propiciar a infecção cruzada pelo manuseio indiscriminado de dentes extraídos e o comércio ilegal de órgãos ${ }^{4}$.

Com isso, os objetivos para a criação de um BDH são de centralizar a arrecadação dos dentes extraídos, difundir e conscientizar a prática de doação de órgãos dentários, viabilizar material para pesquisas provenientes de projetos de iniciação científica e pós-graduação, estudos laboratoriais em nível de graduação nas áreas de Dentística, Endodontia e Prótese, bem como coibir a prática ilegal do comércio de dentes ${ }^{4}$

Um bom funcionamento de um BDH é de extrema importância, já que é fundamental um controle rigoroso dos procedimentos internos do seu processamento, desde o recolhimento dos termos de doação, a limpeza, a separação e o armazenamento ${ }^{4}$ 
A Organização Mundial de Saúde em $2004^{5}$ reconheceu como problema de saúde pública as infecções relacionadas à assistência em saúde. É necessário ressaltar que o BDH é essencial para o controle de infecção cruzada, que existe no manuseio indiscriminado de dentes extraídos ${ }^{4}$. Assim, o BDH tem um papel fundamental na saúde pública, preservando a saúde dos pacientes, alunos e profissionais.

O BDH do DOD-UEM foi criado no ano de 2010 e trata-se de um núcleo sem fins lucrativos, vinculado a Clínica Odontológica da instituição com a participação de docentes e discentes voluntários, com o objetivo de documentar a procedência e o destino dos dentes humanos extraídos, a fim de suprir as necessidades acadêmicas para o aprendizado dos alunos, para o uso em laboratório e treinamento pré-clínico, bem como o fornecimento de dentes humanos para a pesquisa tanto na graduação quanto na pós-graduação.

O objetivo deste trabalho é realizar uma revisão da literatura quanto à existência dos BDHs no Brasil, além de relatar particularmente a experiência do BDH da Universidade Estadual de Maringá, descrevendo suas limitações e importância para a Universidade e sua comunidade acadêmica.

\section{REVISÃO DA LITERATURA}

O primeiro BDH no Brasil foi criado em 1996, na Faculdade de Odontologia da Universidade de São Paulo $\left(\right.$ USP) ${ }^{6}$ e em decorrência de sua experiência, foi formulada em 1997 a Lei n. 9.434 (4 de Fevereiro de 1997), na qual os dentes humanos passaram a ser reconhecidos como órgãos ${ }^{7}$. Essa lei dispõe a remoção de órgãos, tecidos e partes do corpo humano para fins de transplante, tratamento e outras providências $^{8}$. Com isso, a Faculdade de Odontologia da USP tem sido considerada modelo para implantação de BDHs no Brasil.

Com a atual legislação brasileira, a exigência de dentes no ensino, tanto para a finalidade didática quanto para utilização em pesquisas, trouxe à tona questionamentos éticos em torno do comércio ilegal de dentes humanos ${ }^{7}$. Visando minimizar essa atividade, os BDHs foram criados no Brasil por volta dos anos 2000 nas instituições de ensino superior ${ }^{9}$. Além disso, tem como objetivo desenvolver uma percepção de biossegurança e bioética para os discentes e profissionais de Odontologia, assim, estes são responsáveis pelas atividades de recepção, preparação, desinfecção, manipulação, seleção, preservação, catalogação, estocagem, empréstimo, administração dos dentes doados e educação para a ética 9 .

Em 2001, num estudo para verificar o estágio da organização dos BDHs nas instituições brasileiras de ensino superior em Odontologia, 113 instituições foram contatadas, $36(31,9 \%)$ responderam e destas apenas nove (25\%) declararam ter um $\mathrm{BDH}^{10}$. Após 8 anos, outro estudo foi realizado e foram contatadas 187 instituições de ensino superior, 57 (30\%) responderam e 37 destas $(64,91 \%)$ declararam possuir um $\mathrm{BDH}^{6}$. O número de instituições que declararam possuir um BDH aumentou de $25 \%$ para $64,91 \%$ nos oito anos que distanciam os dois estudos ${ }^{6}$. No estudo de 2009 mostrou que há BDHs em todas as regiões brasileiras, enquanto em 2001, não foram identificados BDHs nas regiões Norte e Centro-Oeste ${ }^{10}$.

Na Resolução n. 347, de 13 de janeiro de 2005, o Conselho Nacional de Saúde regulamentou a necessidade do armazenamento e a utilização de material biológico humano no âmbito de projetos de pesquisa e foi determinado que o material biológico deveria ser armazenado sob a responsabilidade de instituição depositária, a qual terá norma ou regulamento aprovado pelo Comitê de Ética em Pesquisa (CEP) dessa instituição ${ }^{7}$. Portanto, os BDHs tiveram que se adaptar a Resolução e estarem dentro das normas para o CEP de cada Universidade.

Desde então, a conscientização das instituições e o protocolo de doação, armazenamento e utilização de dentes humanos vem aumentando juntamente com o aparecimento de BDH na maioria das escolas de Odontologia do Brasil. Assim, o comércio ilegal de dentes vai sendo ainda mais divulgado, e estudos são realizados por meio da utilização de dentes armazenados corretamente com o consentimento livre e esclarecido do paciente que fez a doação ${ }^{7}$.

Apenas alguns BDHs foram relatados nas Universidades brasileiras na literatura e suas características estão dispostas na Tabela 1. Os BDHs diferem quanto ao seu funcionamento e normas estabelecidas pela instituição de ensino, porém seu propósito de suprir as necessidades acadêmicas fornecendo dentes humanos para pesquisas e atividades didáticas são semelhantes.

A USP, como pioneira, conta com uma estruturação modelo para as demais instituições e faz consultorias para a formação de $\mathrm{BDHs}^{11}$. $\mathrm{Na}$ Universidade Federal do Amazonas (UFAM), o BDH iniciou como projeto de extensão relacionado à Endodontia, sendo que os participantes mantém um sítio de informações sobre o seu funcionamento e atividades no site da faculdade e em redes sociais, as doações recebidas são internas e externas, os dentes são limpos, separados e armazenados em água destilada em uma temperatura de $-20^{\circ}$ e são fornecidos para aulas e pesquisas ${ }^{12}$. A Universidade do Oeste de Santa Catarina (Unoesc) começou seu BDH com a doação dos órgãos pelos professores e teve como motivo a aceitação de pesquisas envolvendo dentes humanos pelo CEP apenas com origem comprovada. Os dentes também são limpos, separados e armazenados em água destilada e em refrigeradores. Nesta Universidade o BDH tem vínculo com um projeto de extensão ${ }^{13}$. Na Universidade Federal de Santa Maria (UFSM) o BDH está vinculado à disciplina de Odontopediatria e tem como objetivo fornecer dentes decíduos aos professores, acadêmicos e profissionais que necessitam utilizá-los. A arrecadação é realizada por meio da associação de crianças no Clubinho do Banco de Dentes que são os doadores do órgão dentário, sendo os dentes decíduos limpos, esterilizados na autoclave e armazenados em água comum sob refrigeração ${ }^{14}$.

A Universidade Estadual de Montes Claros (UNIMONTES) também compreende o $\mathrm{BDH}$ como projeto de extensão, os participantes tem a função de divulgar além de realizarem a limpeza, armazenamento e distribuição dos dentes, as questões éticas do BDH são estudadas na disciplina de Bioética da Universidade e as pesquisas podem ser realizadas com a utilização dos órgãos do banco, assim integra-se extensão, ensino e pesquisa, os quais são pilares para as instituições de ensino superior ${ }^{15}$.

$\mathrm{Na}$ Universidade do Estado do Rio de Janeiro (UERJ), o BDH tem caráter multidisciplinar resultante do trabalho vinculado ao Programa de Educação Tutorial (PET), por meio de projeto de extensão, com a orientação do professor tutor ${ }^{16}$. Além das atividades operacionais de captação, limpeza, catalogação e armazenamento de dentes humanos; o BDH da UERJ oferece suporte às atividades didático-científicas e desenvolve ações de conscientização quanto ao emprego de dentes humanos no ensino e na pesquisa $^{16}$. 
Tabela 1. Bancos de Dentes Humanos de Universidades brasileiras de acordo com a literatura estudada.

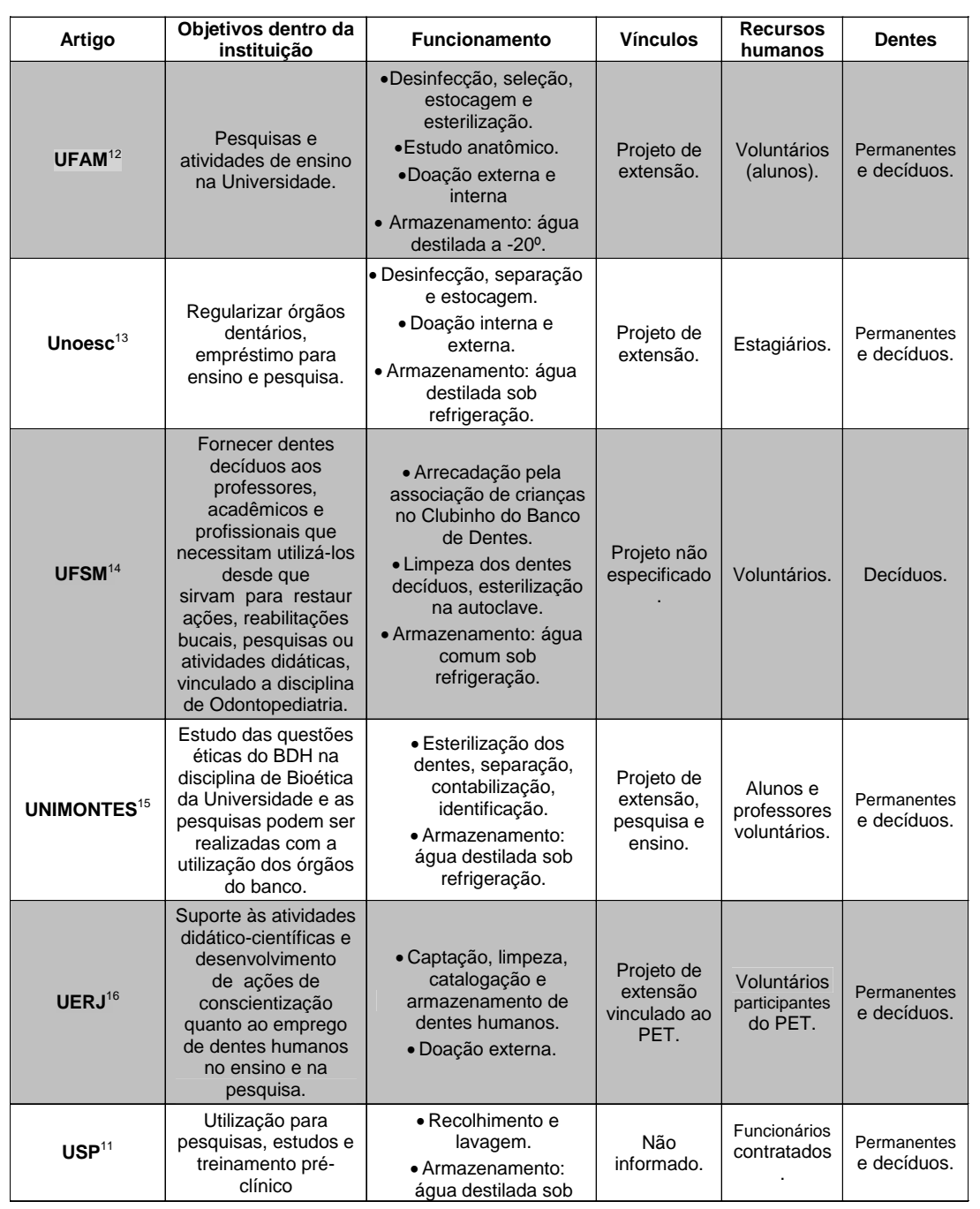

\section{RELATO DE EXPERIÊNCIA DO BHD-UEM}

O BDH-UEM foi criado em 2011 e atualmente conta com a participação ativa de 4 voluntários docentes, sendo um coordenador geral, 5 alunos da graduação, com estrutura física de uma sala contendo potes para separação e estocagem, curetas para a limpeza dos dentes, pia e geladeira para o armazenamento dos mesmos.

O BDH-UEM não é projeto de ensino, pesquisa ou extensão, sendo criado como um órgão vinculado à Clínica Odontológica. Não há qualquer financiamento externo, sendo que os recursos financeiros, humanos e estruturais são obtidos exclusivamente pela Clínica.

O funcionamento do BDH-UEM consiste em várias etapas, iniciando pela arrecadação dos dentes, com o devido preenchimento do termo de consentimento livre e esclarecido de cada doador ou responsável. Há um controle do número de dentes em estoque, por meio de fichas específicas, e o número de dentes é anotado quando entram e saem, bem como a data de movimentação. $O$ consentimento de doação dos dentes extraídos recolhidos e armazenados por cirurgiões-dentistas, estudantes de graduação ou indivíduos da população em geral deve ser obtido no momento do recolhimento dos dentes.

A utilização dos dentes no ensino da graduação se dá por meio de empréstimo aos estudantes e, ao fim das disciplinas solicitantes, os dentes são devolvidos ao banco, independentemente do grau de desgaste ou destruição que apresentarem.

Quando se trata da utilização na pesquisa, os dentes são fornecidos por cessão ou empréstimo, dependendo do tipo de teste a que serão submetidos durante a pesquisa em questão. Em todos os casos, primeiramente o estudante ou o pesquisador deverá preencher cadastro, termos de solicitação e compromisso de citação para que se tenha controle de sua destinação final. Após isso, um projeto deverá ser anexado juntamente com o parecer favorável do Comitê de Ética em Pesquisa Envolvendo Seres Humanos da UEM (COPEP/UEM) para realização do trabalho. Previamente a aprovação da COPEP, é necessária a comprovação da origem dos dentes que serão utilizados na pesquisa. Assim, o BDH providência a declaração de oferecimento do material para determinado estudo, mas os dentes somente são liberados para a pesquisa após a apresentação do parecer conclusivo do COPEP.

Após serem cumpridos os aspectos legais quando recebidos ou coletados na Clínica da instituição, os dentes sofrem processos de desinfecção, limpeza e armazenamento de acordo com o Fluxograma 1 .

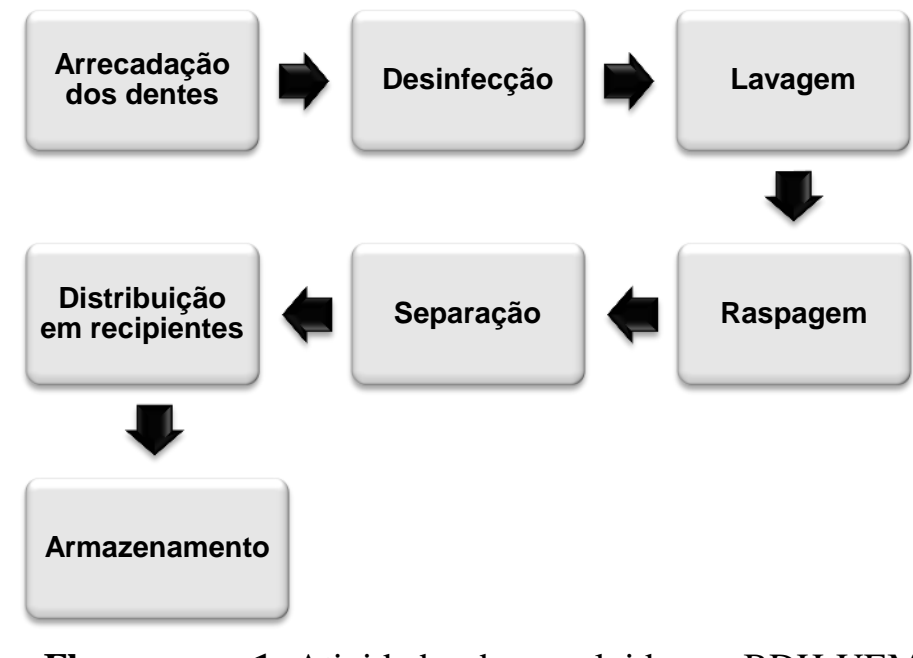

Fluxograma 1: Atividades desenvolvidas no BDH-UEM.

A desinfecção ocorre na sala de esterilização da Clínica e apresenta-se dividida em processos de lavagem prévia dos dentes em água corrente, detergente e escova. Após esse processo realiza-se a raspagem dos dentes para a remoção de restos orgânicos por meio de curetas periodontais. Assim, os dentes são separados e distribuídos em recipientes identificados em seu respectivo grupo dentário (incisivos, caninos, pré-molares e molares, assim como permanentes e decíduos).

De acordo com Imparato et al. ${ }^{17}$ ainda existem incertezas sobre a melhor solução para o armazenamento de dentes, sendo necessária a realização de pesquisas para determinar uma substância ideal, sendo proposto o uso de soro fisiológico, água, formol, cloramina, etanol, timol, azida de sódio dentre outros. No BDH-UEM é feito o armazenamento do dente em água comum e refrigerado a $4^{\circ} \mathrm{C}$, em solução de $5 \mathrm{ml}$, que deve ser trocada semanalmente e após a troca, sua solução descartada.

Os recipientes são separados mensalmente e identificados com etiquetas contendo o número de dentes, seu grupo e data da última troca da solução de armazenamento. Há atualização constante dos números de dentes para controle do fluxo de entrada e saída.

Mesmo se o dente vier sem identificação, nenhum dente é descartado, pois constitui de material biológico que poderá ser reaproveitado para o ensino. A retirada ou a chegada de dentes, assim como a identificação dos mesmos, é anotada em fichas específicas de controle de entrada e saída, na qual deve constar a assinatura do responsável pelo estoque de dentes.

Por meio de requisições, os alunos e docentes fazem os pedidos e os dentes podem ser disponibilizados para pesquisa ou ensino após análise pela Comissão do BDH, e se pertinente, os dentes são cedidos.

\section{DISCUSSÃO}

Os objetivos principais do BDH-UEM são: a) auxílio em pesquisas utilizando órgãos dentários, b) controle de infecção, c) evitar o comércio ilegal de dentes, bem como ressaltar as questões éticas quanto aos órgãos e 
conscientização dos profissionais da Odontologia, docentes e discentes da Universidade ${ }^{3,4}$.

$\mathrm{O}$ funcionamento de todos os BDHs segue basicamente o mesmo protocolo de coleta, limpeza e armazenamento nas instituições estudadas ${ }^{11-16}$, porém nessa última etapa, diferentemente dos outros bancos, na UEM e na UFSM ${ }^{14}$, observou-se que o armazenamento dos dentes é realizado em água comum, ao invés de água destilada como na maioria dos BDHs. Na UEM ocorre assim, pois falta financiamento necessário para a manutenção desse método de armazenamento, já que todo recurso adquirido para a manutenção de suas atividades é advindo da Clínica.

Nas Universidades UFAM ${ }^{12}$ Unoesc ${ }^{13}$, UNIMONTES $^{15}$, UERJ $^{16}$ e USP ${ }^{11}$ são coletados dentes permanentes e decíduos, igualmente a UEM, porém na UFSM $^{14}$ ocorre apenas com dentes decíduos, por ser direcionado a disciplina de Odontopediatria.

O BDH da UEM é vinculado apenas à Clínica, e não é projeto de ensino, pesquisa e extensão e não pertence a nenhum outro programa. Em outras experiências, isto não ocorre. Por exemplo, na UERJ ${ }^{16}$, o projeto é vinculado ao PET e enquadra-se em um projeto de extensão, em que trabalha diversas ações de conscientização junto ao público externo da Universidade, ocorrendo maior aproximação entre o $\mathrm{BDH}$ e a comunidade, desse modo ampliando a captação de dentes por meio de outras fontes além da faculdade e motivando os pacientes para a doação, além de buscar conscientizar os próprios alunos da instituição ${ }^{16}$. No BDH-UEM ainda é observado uma lacuna nessa área.

Na UNIMONTES ${ }^{15}$ ocorre uma maior divulgação do projeto, na qual a questão ética do $\mathrm{BDH}$ é estudada pela disciplina de Bioética oferecida pela Universidade e ocorre um contato direto de todos os alunos com a utilização da estrutura física no BDH na aula prática da disciplina de anatomia especial ${ }^{15}$. Na UFAM e na Unoesc, o BDH tem funcionamento por meio de projetos de extensão e conta com a participação de docentes e discentes ${ }^{12,13}$. Vale ressaltar que nota-se a escassez de dados na literatura internacional sobre os bancos de dentes e as questões éticas que os envolvem ${ }^{6}$.

Uma restrição observada em todos os BDHs é que a maioria dos pacientes não tem a correta informação sobre a existência deste banco e sua importância, e devido a isso nem todos aceitam fazer a doação desse órgão. Muitos alunos da própria instituição não tem a informação adequada sobre o funcionamento do $\mathrm{BDH}$, o que prejudica na hora de intervir de melhor forma no momento da coleta $^{6,16}$. Por isso, os objetivos da coordenação do BDH na UEM é ampliar a divulgação, receber dentes de doações externas e doar/emprestar para os alunos utilizarem no ensino das práticas laboratoriais.

Nassif et al. ${ }^{11}$ mencionaram que para o bom funcionamento de um $\mathrm{BDH}$, é fundamental um controle severo de seus procedimentos internos, que incluem a separação e o estoque de dentes, assim como o cadastro e o arquivamento das fichas dos doadores e beneficiários. $\mathrm{O}$ BDH-UEM faz questão de registrar e controlar a entrada e saída dos dentes humanos, bem como o correto preenchimento de todas as fichas necessárias para a doação do material. Além disso, a biossegurança é essencial na coleta, limpeza e manuseio desses dentes, implementando uma educação permanente ${ }^{18}$.

O BDH-UEM almeja se tornar projeto de extensão, pesquisa ou ensino para a busca de financiamento, bem como a utilização dos dentes recolhidos e armazenados para suporte nas atividades didático-científicas como estudos e treinamentos pré-clínicos, porém este objetivo ainda não foi alcançado.

Na UEM há acadêmicos do curso de Odontologia que compõem o BDH, e estão inseridos na clínica ampliada e de cirurgia, que são responsáveis por fiscalizar o preenchimento dos formulários e orientar os alunos para recolherem os dentes corretamente.

A demanda de dentes para sustentar todos os alunos em laboratório é grande nas Universidades ${ }^{4}$. Na UEM, ainda não foi possível cumprir este objetivo e disponibilizar dentes para todos os alunos no ensino. Outra limitação verificada em todos os BDHs ${ }^{11-16}$, com exceção da USP, está relacionada a presença de funcionários contratados. $\mathrm{Na}$ maioria dos BDHs, o funcionamento do serviço ocorre pela cooperação de docentes e discentes de forma voluntária.

Além disso, o BDH necessita ser mais divulgado na comunidade interna e externa da instituição com intuito de incentivar as doações, conscientizar sobre a importância cultural, bioética, social, legal e moral da existência de um BDH. Para isso há sugestões para a divulgação por meio de atividade educativas, redes sociais, congressos, palestras, cartazes e folders que serão inseridos como proposta para o BDH-UEM.

\section{CONCLUSÃO}

Apesar de o BDH-UEM apresentar suas limitações, seu funcionamento é de extrema importância para a Universidade, para os alunos e para a população, valorizando o dente como órgão, evitando o comércio ilegal, diminuindo as fontes de infecção cruzada além de apoiar o desenvolvimento e a execução de pesquisas científicas.

\section{REFERÊNCIAS}

1. Brasil. Lei $\mathrm{n}^{\circ} 9.434$ de 4 de fevereiro de 1997. Disponível em: http://www.planalto.gov.br. Acesso em: 03 mar. 2017.

2. Moreira L, Genari B, Stello R, Collares FM, Samuel SMW. Banco de dentes humanos para o ensino e pesquisa em Odontologia. Rev Fac Odontol Porto Alegre. 2009; 50(1):34-7.

3. Paula S, Bittencourt LP, Pimentel E, Gabrielli Filho PA, Imparato JCP. Comercialização de dentes nas Universidades. Pesq Bras Odontoped Clin Integr. 2001; 1(3):38-41.

4. Nassif ACS, Tieri F, Ana PA, Botta SB, Imparato JCP. Estrutura de um Banco de Dentes Humanos. Pesqui Odontol Bras. 2003; 17(Supl 1):70-4.

5. World Health Organization. Practical guidelines for infection control in healthcare facilities. Geneva; 2004. Disponível em: http://www.wpro.who.int/ publications/ docs/practical_guidelines_infection_control.pdf. Acesso em: 4 dez. 2017.

6. Freitas ABDA, Pinto SL, Tavares EP, Barros LM, Castro CDL, Magalhães CS. Uso de dentes humanos extraídos e os bancos de dentes nas instituições brasileiras de ensino de Odontologia. Pesq Bras Odontoped Clin Integr. 2012; 12(1):59-64.

7. Gomes GM, Gomes GM, Pupo YM, Gomes OMM, Schmidt LM, Koszlowski Junior VA. Utilização de dentes humanos: aspectos éticos e legais. Rev Gaúcha Odontol. 2013; 61(0):477-83.

8. Brasil. Conselho Nacional de Saúde. Diretrizes para análise ética de projetos de pesquisa que envolva armazenamento de materiais ou uso de materiais armazenados em pesquisas anteriores. 
Brasília (DF); 2005.

9. Pereira DQ. Banco de dentes humanos no Brasil: revisão de literatura. Revista da ABENO. 2012; 12(2):178-84.

10. Begosso MP, Imparato JCP, Duarte DA. Estágio atual da organização dos bancos de dentes humanos nas faculdades de Odontologia do território brasileiro. Rev Pós-Grad. 2001; 8(1):23-8.

11. Nassif ACS, Tieri F, Ana PA, Botta SB, Imparato JCP. Estruturação de um banco de dentes humanos. Pesqui Odontol Bras. 2003; 17(Supl 1):70-4.

12. Sponchiado Júnior EC, Guimarães CC, Marques AAF, Rebelo MAB, Conde NCO, Bandeira MFCL et al. Banco de dentes humanos e educação em saúde na Universidade Federal do Amazonas. Relato de experiência. Revista da ABENO. 2012; 12(2):185-9.

13. Ghiggi LD, Dallanora LMF. Implantação do banco de dentes humanos $(\mathrm{BDH})$ do curso de Odontologia da Universidade do Oeste de Santa Catarina. Ação Odonto. 2014; 2:61-71.

14. Marin EA, Zorzin D, Minardi APR, Oliveira MDM. Estruturação do banco de dentes humanos decíduos da Universidade Federal de Santa Maria/RS/Brasil. Rev Fac Odontol Univ Passo Fundo. 2005; 10(2):7-9.

15. Costa SM, Lima EB, Mameluque S, Pires CPAB, Melo AEMA, Souza GRP. Banco de dentes humanos da UNIMONTES: Relato de experiência de integração ensino pesquisa e extensão. Rev Intercâmbio. 2013; 4:247-52.

16. Louzada LN, Jorge RC, Silva KS, Pacífico RSL, Dantas FFP, Novaes SEA, et al. Banco de dentes humanos: ética a serviço do ensino e da pesquisa - a experiência da Faculdade de Odontologia da UERJ. Interagir: pensando a extensão. 2015; 20: 67-79.

17. Imparato JCP. Banco de dentes humanos. Curitiba: Editora Maio; 2008.

18. Galicioli SM, Baratieri T, Lenstck MH. Biossegurança em Odontologia: O uso de minimanual como estratégia de educação permanente. Revista Espaço para a saúde. 2015; 16(4):120-7.

\section{CONFLITO DE INTERESSES}

Os autores declaram não haver conflitos de interesse.

\section{AUTOR PARA CORRESPONDÊNCIA}

\section{Marcos Sérgio Endo}

marcossendo@gmail.com

Submetido em 11/08/2017

Aceito em 11/09/2017 